\title{
Safeness of Diets Based on Gluten-Free Buckwheat Bread Enriched with Seeds and Nuts-Effect on Oxidative and Biochemical Parameters in Rat Serum
}

\author{
Michal Świeca ${ }^{1}{ }^{\oplus}$, Julita Regula ${ }^{2, *}{ }^{\oplus}$, Joanna Suliburska ${ }^{2}$, Urszula Zlotek $^{1} \oplus$, \\ Urszula Gawlik-Dziki ${ }^{1} \mathbb{D}$ and Isabel M. P. L. V. O. Ferreira ${ }^{3}$ \\ 1 Department of Biochemistry and Food Chemistry, University of Life Sciences, Skromna Str. 8, \\ 20-704 Lublin, Poland; michal.swieca@up.lublin.pl (M.Ś.); urszula.zlotek@up.lublin.pl (U.Z.); \\ urszula.gawlik@up.lublin.pl (U.G.-D.) \\ 2 Institute of Human Nutrition and Dietetics, Poznan University of Life Sciences, Wojska Polskiego Str. 31, \\ 60-624 Poznan, Poland; joanna.suliburska@up.poznan.pl \\ 3 LAQV/REQUIMTE, Laboratório de Bromatologia e Hidrologia, Departamento de Ciências Químicas, \\ Faculdade de Farmácia, Universidade do Porto, 4051-401 Porto, Portugal; isabel.ferreira@ff.up.pt \\ * Correspondence: julita.regula@up.poznan.pl; Tel.: +48-61-848-73-39
}

Received: 19 November 2019; Accepted: 19 December 2019; Published: 22 December 2019

\begin{abstract}
Buckwheat breads enriched with seeds (e.g., poppy, carum, amaranth, sunflower, and pumpkin) and nuts can be excellent sources of selected macro- and microelements and bioactive components, such as phenolics, essential oils, unsaturated fatty acids, fiber, and vitamins; however, no studies described their impacts on body biochemical parameters and antioxidant status. The aim of this study was to a determine the safety (the analyses of blood morphological and biochemical parameters) of short-term diets based on buckwheat breads supplemented with the commonly used functional ingredients. Additionally, we confirmed the usefulness of these fortified breads in a reduction of blood cholesterol and triacylglycerols, as well as an improvement of in vivo antioxidant status of Wistar rats. Enriched breads presented an increased phenolic content; however, it has not been translated into an elevation of antioxidant capacities. During short-term in vivo experiments, the studied breads increased the body mass of the rats, except the control buckwheat bread. Compared to the control, the poppy-milk bread markedly lowered $(-23 \%)$ and egg yolk-carum bread significantly increased $(+17 \%)$ the total cholesterol concentration in serum. All the fortified breads decreased triacylglycerols' levels by about $50 \%$. Bread enriched with the poppy-milk, milk-seed, egg yolk-carum, and a mix of additives decreased superoxide dismutase activity by $68 \%, 66 \%, 73 \%$, and $71 \%$, respectively. Catalase activity was significantly decreased in the rats fed with carum bread $(-62 \%)$ and markedly increased in the groups fed with egg yolk-carum bread $(+89 \%)$, hazel nuts-amaranth bread $(+72 \%)$, and milk-seeds bread $(+65 \%)$. The results confirmed the usefulness and safety of functional additives in buckwheat breads.
\end{abstract}

Keywords: antioxidant status; bread enrichment; buckwheat; gluten free bread; lipid profile

\section{Introduction}

Bread is the most popular staple food in the world due to its nutritive value, low price, and simplicity of usage and production. Bread is mainly produced from wheat and rye flours; however, in the last years, there has been a growing interest in alternative crops (amaranth, quinoa, buckwheat, etc.) [1]. This trend results from two main reasons. In populations, there is a group of people for whom consumption of prolamins, protein fraction commonly present in wheat, rye, barley, and oats, causes some disorders e.g., coeliac disease, allergy, and non-celiac sensitivity to gluten [2]. On the other hand, 
in modern communities, there is a kind of trend toward adopting a gluten-free diet, which is pointed out as promoting well-being and improving consumers' health [1,3].

The main alternative gluten-free crops for bread production are amaranth, quinoa, rice, and buckwheat [1]. Buckwheat, belonging to the Polygonaceae family, has received increasing attention as a potential functional food not only for bread, but also for cookies, pasta, noodles, and beer [1]. It is a rich source of starch (55-70\%), including resistant starch (30-35\%) [3,4] and proteins (8-19\%) of high biological quality [3]. Additionally, it also contains valuable trace elements (zinc, copper, manganese, iron, potassium, phosphorus, magnesium, boron, cobalt, and platinum) and dietary fiber [3,5]. Buckwheat is also a rich source of phenolics, such as rutin, quercetin, quercitrin, orientin, homoorientin, vitexin, and isovitexin - flavonoids with well-documented pro-health properties $[6,7]$.

So far, buckwheat flour has been successfully added to many food products, to increase flavonoid, mineral, and resistant starch contents [8]. To meet consumers' needs and preferences, some optional ingredients can be added to enhance nutritional and nutraceutical quality and also improve organoleptic characteristics. Buckwheat breads enriched with seeds (e.g., poppy, carum, amaranth, sunflower, and pumpkin) and nuts, can be excellent sources of selected macro- and microelements and bioactive components, such as phenolics, essential oils, unsaturated fatty acids, fiber, and vitamins [8]; however, so far, there are no studies that describe their safeness and impact on body biochemical parameters and antioxidant status. A wide range of studies concerning the safety of diets enriched with functional ingredients and evaluation of potential positive and/or negative effects of such products is of major relevance. These studies were designed to investigate the safety (the analyses of blood morphological and biochemical parameters) of short-term diets containing buckwheat breads supplemented with the commonly used functional ingredients. Additionally, they are aimed to confirm the usefulness of these fortified breads in a reduction of blood cholesterol and triacylglycerols, as well as in an improvement of in vivo antioxidant status of Wistar rats.

\section{Materials and Methods}

\subsection{Bread Preparation}

All breads analyzed in this study were produced from buckwheat. Natural components commonly available on the market were used to enrich the buckwheat bread: B1-bread enriched with milk and poppy; B2-bread enriched with carum, amaranth, and seeds; B3-bread enriched with hazel nuts, seeds, and amaranth flour; B4—bread enriched with milk, amaranth flour, and seeds; B5—bread enriched with amaranth flour, seeds, yolk, and carum; B6-bread enriched with milk, amaranth flour, seeds, and poppy. Buckwheat bread was used as the control bread (BC), without supplements (Table 1). To prepare the bread, the following ingredients were also used: potato and corn starch (Glutenex Company, Sady, Poland), rapeseed oil (Kruszwica, Poland), salt (Solino, Poland), fresh yeast (Saccharomyces cerevisiae) (Lesaffre, Warsaw, Poland), and saccharose (Pfeifer \& Langen, Gostyn, Poland), milk powder (SM Mlekovita, Wysokie Mazowieckie, Poland), poppy seeds (VOG, Skierniewice, Poland), sunflower seeds (VOG, Skierniewice, Poland), flax seeds (Bio Planet, Leszno (Masovian Voivodeship), Poland), pumpkin seeds (VOG, Skierniewice, Poland), egg yolk (Ovovita, Rzgow. Poland), carum (KOTÁNYI, Warsaw, Poland), hazel nuts (VOG, Skierniewice, Poland), and amaranth (Bio Planet, Leszno (Masovian Voivodeship), Poland). 
Table 1. Buckwheat breads' composition.

\begin{tabular}{|c|c|c|c|c|c|c|c|}
\hline $\begin{array}{l}\text { Ingredients } \\
(\%)\end{array}$ & \multicolumn{7}{|c|}{ Breads } \\
\hline buckwheat flour & 20.7 & 19.7 & 17.2 & 17.7 & 17.2 & 17.4 & 16.6 \\
\hline $\begin{array}{l}\text { corn and potato } \\
\text { starch ( } \% \text { potato) }\end{array}$ & $31.1(20.7)$ & $24.2(14.3)$ & $19.4(10.8)$ & $19.9(11.1)$ & $19.4(10.8)$ & $19.6(10.9)$ & $18.7(10.4)$ \\
\hline $\begin{array}{l}\text { Saccharomyces } \\
\text { cerevisiae }\end{array}$ & 2.6 & 2.5 & 2.2 & 2.2 & 2.2 & 2.2 & 2.1 \\
\hline saccharose & 3.1 & 3.0 & 2.6 & 2.7 & 2.6 & 2.6 & 2.5 \\
\hline $\mathrm{NaCl}$ & 0.5 & 0.5 & 0.4 & 0.4 & 0.4 & 0.4 & 0.4 \\
\hline rapeseed oil & 0.5 & 0.5 & 0.4 & 0.4 & 0.4 & 0.4 & 0.4 \\
\hline milk powder & - & 3.0 & - & - & 2.6 & - & 2.5 \\
\hline sunflower seeds & - & - & 2.2 & 2.2 & 1.7 & 2.2 & 2.1 \\
\hline pumpkin seeds & - & - & 2.2 & 2.2 & 2.2 & 2.2 & 2.1 \\
\hline hazel nuts & - & - & 1.7 & 2.7 & 1.7 & 2.2 & 2.1 \\
\hline poppy & - & 7.4 & - & 2.2 & 2.6 & - & 4.1 \\
\hline egg yolk & - & - & 0.4 & - & - & 0.9 & 0.4 \\
\hline carum & - & - & 4.3 & - & - & 2.6 & 0.0 \\
\hline water & 41.5 & 39.4 & 42.2 & 42.5 & 42.2 & 42.6 & 41.5 \\
\hline
\end{tabular}

\subsection{Animals and Diets}

The study was conducted for 14 days on 42 male rats (6 weeks old) of the albino Wistar strain, with a mean body weight of $234.1 \mathrm{~g} \pm 25.6$. The experiment was performed with the agreement of the local bioethics committee (approval no. 888/11). Animals were kept in a thermostatically controlled room $\left(22^{\circ} \mathrm{C} \pm 2\right)$, in a $12 \mathrm{~h}$ light/dark cycle, at 55-60\% humidity, with unlimited access to distilled water (ad libitum). The animals were divided into seven groups. They were fed an AIN93M diet [9] with a $70 \%$ addition of gluten-free breads (control group BC-diet enriched with bread without functional supplements) and six group with breads enriched with supplements (B1-bread enriched with milk and poppy; B2-bread enriched with carum, amaranth, and seeds; B3-bread enriched with hazel nuts, seeds, and amaranth flour; B4-bread enriched with milk, amaranth flour, and seeds; B5—bread enriched with amaranth flour, seeds, yolk, and carum; B6-bread enriched with milk, amaranth flour, seeds, and poppy). The food consumption was recorded daily, and the animals were weighed once a week. At the completion of the feeding period on the last day of the experiment, after $12 \mathrm{~h}$ of fasting, the animals were euthanized with a sodium thiopental injection ( $40 \mathrm{mg} / \mathrm{kg}$ body weight). Blood was then collected from the left heart chamber.

Energy and nutrients intake were calculated according to USDA National Nutrient Database [10]. The nutritional value of the diets with gluten-free breads is shown in Table 2. 
Table 2. Approximate energy, fiber, fat, and unsaturated fatty acids intake and mean body mass in rats.

\begin{tabular}{|c|c|c|c|c|c|}
\hline & Energy * (kcal) & Fiber * $(\%)$ & Fat * $(\%)$ & $\begin{array}{c}\text { Unsaturated Fatty } \\
\text { Acids* }(\%)\end{array}$ & $\begin{array}{l}\text { Body Mass } \\
\text { Change (g) }\end{array}$ \\
\hline $\mathrm{BC}$ & 166.90 & 3.29 & 1.71 & 0.23 & $-14.67 \pm 2.58 \mathrm{a}$ \\
\hline B1 & 191.16 & 4.47 & 3.40 & 2.33 & $3.67 \pm 10.67 b$ \\
\hline B2 & 190.32 & 4.55 & 6.78 & 0.99 & $4.33 \pm 5.16 b$ \\
\hline B3 & 197.00 & 4.26 & 6.82 & 1.42 & $5.67 \pm 6.02 b$ \\
\hline B4 & 196.00 & 4.29 & 6.44 & 1.45 & $10.67 \pm 8.02 b$ \\
\hline B5 & 187.31 & 4.22 & 6.58 & 0.95 & $9.50 \pm 4.51 b$ \\
\hline B6 & 204.72 & 4.53 & 7.31 & 1.97 & $7.75 \pm 7.58 b$ \\
\hline
\end{tabular}

BC-control bread; B1—bread enriched with milk and poppy; B2—bread enriched with carum, amaranth, and seeds; B3-bread enriched with hazel nuts, seeds, and amaranth flour; B4-bread enriched with milk, amaranth flour, and seeds; B5-bread enriched with amaranth flour, seeds, yolk, and carum; B6-bread enriched with milk, amaranth flour, seeds, and poppy. Means ( $n=6, \pm$ standard deviation) followed by different lower-case letters between breads are significantly different at $p<0.05$. ${ }^{*}$ Calculated according to USDA National Nutrient Database.

\subsection{Gastrointestinal Digestion In Vitro}

Evaluation of total phenolic content and antioxidant capacity of breads was performed on the bio-accessible fraction obtained after in vitro simulation of gastrointestinal digestion [4].

\subsection{Analysis of Blood Morphological and Biochemical Parameters}

The blood was collected by cardiac puncture in tubes with heparin sodium, to obtain whole blood for morphological tests and in serum-separated tubes for biochemical parameters. The coagulated blood was left to clot at room temperature for $30 \mathrm{~min}$, and then it was centrifuged for $15 \mathrm{~min}$ at $3600 \times g$. The following morphological and biochemical parameters were determined: white blood cells (WBC), mean corpuscular volume (MCV), mean corpuscular hemoglobin (MCH), mean corpuscular hemoglobin concentration (MCHC), lymphocytes (LYM), platelet distribution width (PDW), red blood cell distribution width (RDW), mean platelet volume (MPV), glucose (GLU), albumins (ALB), triacylglycerols (TAG), alanine transaminase activity (ALA), aspartate transaminase activity (AST), total cholesterol (TCH), and high-density lipoprotein cholesterol (HDL). Values for the morphological indices were determined by using a Sysmex K-1000 hematological analyzer (TAO Medical Electronics Co., Kobe, Japan) according to the standard procedures. The concentration of glucose in the blood serum was estimated by the glucose oxidase method. Total cholesterol and triglyceride levels in serum were measured by using commercial kits (Randox Laboratory Ltd., UK). Albumin was measured by the immunoassay method, using a rat kit. The activities of liver enzymes, such as ALT and AST, were determined according to Dembinska-Kiec and Nastalski [11].

\subsection{Total Phenolics Content}

Total phenolics content in bread was estimated according to the Folin-Ciocalteu method [12]. The amount of total phenolics was expressed as gallic acid equivalents (GAE).

\subsection{Antioxidant Capacity}

\subsubsection{Antiradical Activity (ABTS)}

The ability to quench free radicals of digested bread extracts and rat serum were determined by using an improved ABTS decolorization assay [13]. Antiradical activity was expressed as a Trolox equivalent. 


\subsubsection{Ferric Reducing Power (FRAP)}

Reducing powers of digested bread extracts and rat serum were determined by the method of Oyaizu [14]. Reducing power was expressed as a Trolox equivalent.

\subsubsection{Catalase Activity Assay (CAT)}

CAT activity was assayed by the method of Claiborne [15] with some modification [16]. The catalase activity was expressed in $\mathrm{U}$, where $1 \mathrm{U}$ was defined as the amount of enzyme present that decomposed $1 \mu \mathrm{mol}$ of $\mathrm{H}_{2} \mathrm{O}_{2}$ per min (method conditions).

\subsubsection{Superoxide Dismutase Assay (SOD)}

SOD activity was determined by using a kinetic mode [17]. The SOD activity was expressed in $\mathrm{U}$, where $1 \mathrm{U}$ was defined as the amount of enzyme present that produced a change in absorbance of 0.001 per min (method conditions).

\subsection{Statistical Analysis}

Statistical tests were performed by using Statistica 6.0 software (StatSoft, Inc., Tulsa, OK, USA). All data were tested for normal distribution by use of the Shapiro-Wilk test. Normally distributed values were compared, using ANOVA. Means of analyzed traits in the groups were compared, using one-way analysis of variance, while intergroup differences were assessed by Tukey's post hoc test, at the significance level $p<0.05$. Data were evaluated by using Pearson's correlation coefficients, to identify relationships between selected features.

\section{Results and Discussion}

Epidemiological studies indicate an inverse relationship between a high-fiber diet, as well as dietary flavonoids intake and the risk of many disorders, including cardiovascular disease, cancers, and inflammations $[8,18]$. Many studies concerning the composition of buckwheat confirm that these gluten-free seeds present high contents of polyphenols and resistant starch, being an interesting ingredient to be used in functional diets.

The level of potentially bio-accessible phenolics, as well as antiradical activity quantified after in vitro simulation of gastrointestinal digestion of the studied breads, is depicted in Figure 1. Breads enriched with seeds and grains presented an increased phenolic content; however, it has not been translated into an elevation of their antioxidant capacities, since there was no correlation between both features.

Buckwheat-enriched wheat breads are characterized by the increased antioxidant potential due to the presence of rutin [8]. Compared to the previous studies by Świeca et al., [16] concerning rice-based gluten-free bread enriched with functional supplements (analogical to those used in this study) higher phenolic contents and antioxidant capacity was observed in the extracts obtained after in vitro simulation of gastrointestinal digestion of buckwheat breads. However, concerning buckwheat breads the improvement of antioxidant potential was not correlated with the increase of phenolics. It may be due to fact that rice flour contains about 40 times less of polyphenolic than that obtained from buckwheat [19], and the added value (antioxidant capacity of supplements) was masked by extremely high antioxidant potential of buckwheat flour. Additionally, the baking process leads to the formation of new heat-generated compounds, mainly by Maillard reactions, and bread is a complex system. Thus, the use of different ingredients had a variable impact on the overall antioxidant capacity [19]. The basic buckwheat bread (BC) and the studied supplemented bread were characterized by significantly higher antioxidant potential when compared to the wheat bread [8].

In this study, diets enriched with functional components caused an increase of body mass-Table 2 (basic buckwheat breads, which are low in fat and calories), which may be explained by the fact that nuts and seeds are typically high in dietary fat; thus, fortified breads presented increased caloric value, 
as confirmed by the theoretical calculation performed, using standard values taken from the USDA National Nutrient Database (Table 1). However, according to the last studies of Nishi et al. [18], these ingredients are considered to be heart-healthy foods. Additionally, this assumption is supported by the results concerning the lipids profile observed after experiment (Table 3).

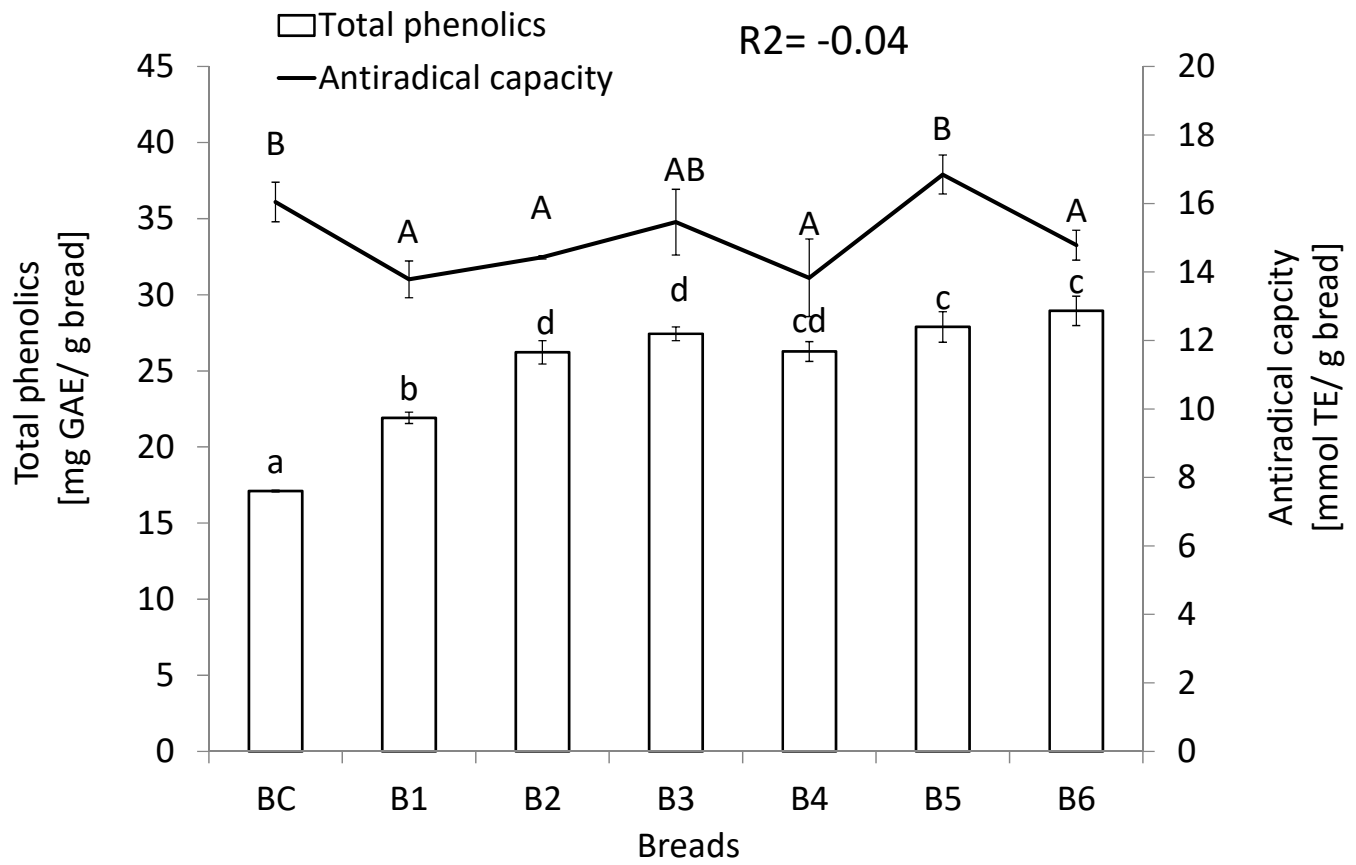

Figure 1. Phenolics content and antiradical capacity of the potential bio-accessible fraction of studied breads. Means ( $n=6, \pm$ standard deviation) followed by different lower-case letters are significantly different at $p<0.05$. BC—control bread; B1—bread enriched with milk and poppy; B2—bread enriched with carum, amaranth, and seeds; B3-bread enriched with hazel nuts, seeds, and amaranth flour; B4-bread enriched with milk, amaranth flour, and seeds; B5-bread enriched with amaranth flour, seeds, yolk, and carum; B6-bread enriched with milk, amaranth flour, seeds, and poppy; TE—Trolox equivalent; GAE—gallic acid equivalent.

Table 3. Influence of buckwheat bread on biochemical parameters in rats.

\begin{tabular}{|c|c|c|c|c|c|c|c|}
\hline & \multirow[b]{2}{*}{ BC } & \multicolumn{6}{|c|}{ Diet } \\
\hline & & B1 & B2 & B3 & B4 & B5 & B6 \\
\hline GLU $\left(\mathrm{mg} \mathrm{dL}^{-1}\right)$ & $117.8 \pm 21.7$ & $139.5 \pm 33.5$ & $118.8 \pm 26.1$ & $111.0 \pm 18.8$ & $102.2 \pm 23.5$ & $130.8 \pm 26.9$ & $109.7 \pm 12.3$ \\
\hline $\operatorname{ALB}\left(\mathrm{g} \mathrm{dL}^{-1}\right)$ & $3.37 \pm 0.1$ & $3.58 \pm 0.1$ & $3.60 \pm 0.1$ & $3.67 \pm 0.1$ & $3.63 \pm 0.2$ & $3.60 \pm 0.2$ & $3.53 \pm 0.1$ \\
\hline $\mathrm{TCH}\left(\mathrm{mg} \mathrm{dL}^{-1}\right)$ & $83.5 \pm 7.2 b$ & $69.3 \pm 3.1 \mathrm{a}$ & $90.1 \pm 14.3 b c$ & $76.8 \pm 9.5 \mathrm{ab}$ & $90.0 \pm 11.8 \mathrm{bc}$ & $97.6 \pm 5.8 \mathrm{c}$ & $79.5 \pm 11.8 \mathrm{ab}$ \\
\hline $\operatorname{HDL}\left(\mathrm{mg} \mathrm{dL}^{-1}\right)$ & $29.4 \pm 3.6 \mathrm{ab}$ & $24.8 \pm 1.8 \mathrm{a}$ & $31.0 \pm 4.1 \mathrm{ab}$ & $26.1 \pm 2.7 \mathrm{ab}$ & $29.9 \pm 3.4 \mathrm{ab}$ & $32.5 \pm 3.2 b$ & $27.8 \pm 1.5 \mathrm{ab}$ \\
\hline $\mathrm{TAG}\left(\mathrm{mg} \mathrm{dL}^{-1}\right)$ & $42.5 \pm 5.9 c$ & $27.8 \pm 4.8 \mathrm{~b}$ & $22.0 \pm 5.5 \mathrm{ab}$ & $20.0 \pm 4.5 \mathrm{ab}$ & $18.3 \pm 3.7 \mathrm{a}$ & $28.1 \pm 12.1 \mathrm{ab}$ & $18.1 \pm 5.8 \mathrm{ab}$ \\
\hline AST $\left(\mathrm{U} \mathrm{L}^{-1}\right)$ & $93.3 \pm 34.7$ & $98.0 \pm 41.1$ & $74.5 \pm 22.0$ & $90.6 \pm 39.3$ & $83.5 \pm 32.2$ & $91.5 \pm 45.4$ & $86.3 \pm 42.2$ \\
\hline $\operatorname{ALT}\left(\mathrm{U} \mathrm{L}^{-1}\right)$ & $27.6 \pm 8.9$ & $23.1 \pm 7.4$ & $21.1 \pm 8.8$ & $19.5 \pm 8.3$ & $16.1 \pm 3.7$ & $20.0 \pm 6.3$ & $21.8 \pm 6.8$ \\
\hline
\end{tabular}

Means ( $n=6, \pm$ standard deviation) followed by different lower-case letters within rows are significantly different at $p<0.05$. BC - control bread; B1—bread enriched with milk and poppy; B2-bread enriched with carum, amaranth, and seeds; B3 - bread enriched with hazel nuts, seeds, and amaranth flour; B4—bread enriched with milk, amaranth flour, and seeds; B5-bread enriched with amaranth flour, seeds, yolk, and carum; B6-bread enriched with milk, amaranth flour, seeds, and poppy; GLU—glucose; ALB — albumins; TCH—total cholesterol TAG-triacylglycerols; ALT_-alanine transaminase; AST—aspartate transaminase; HDL_high-density lipoprotein cholesterol.

The studied gluten-free breads did not significantly influence most of the morphological parameters of rat blood; however, a significant increase in concentration of thrombocytes was observed in the group with poppy-milk bread (Table 4). The relevant changes were observed in the lipid profiles of serum (Table 3). In comparison with BC, the animals fed with B1, B3, and B6 presented a decrease in total cholesterol concentration; however, these changes were significant only in the case of the B1 diet. 
An adverse effect was observed for the B5 diet. Most importantly, rats fed with all the enriched breads had significantly lower levels of triacylglycerols (compared to the BC diet). The lowest levels were determined for B3, B4, and B6 (reduction of $\sim 50 \%-55 \%$ in regard to BC) (Table 4).

Table 4. Effects of bread diets on the blood morphological parameters.

\begin{tabular}{|c|c|c|c|c|c|c|c|}
\hline & \multicolumn{7}{|c|}{ Breads } \\
\hline & BC & B1 & B2 & B3 & B4 & B5 & B6 \\
\hline $\operatorname{WBC}\left(\times 10^{3} \mu \mathrm{L}^{-1}\right)$ & $2.45 \pm 0.87$ & $3.62 \pm 0.76$ & $3.92 \pm 1.28$ & $3.26 \pm 0.63$ & $3.32 \pm 0.83$ & $2.72 \pm 0.99$ & $3.35 \pm 0.80$ \\
\hline Hemoglobin $\left(\mathrm{g} \mathrm{dL}^{-1}\right)$ & $14.15 \pm 0.68$ & $14.07 \pm 0.53$ & $14.07 \pm 0.40$ & $14.08 \pm 0.42$ & $14.32 \pm 0.64$ & $14.18 \pm 0.33$ & $13.92 \pm 0.62$ \\
\hline Hematocrit (\%) & $41.87 \pm 2.81$ & $42.17 \pm 1.42$ & $41.62 \pm 1.60$ & $41.80 \pm 0.83$ & $42.52 \pm 1.96$ & $42.67 \pm 1.24$ & $41.50 \pm 2.46$ \\
\hline $\mathrm{MCH}(\mathrm{pg})$ & $19.70 \pm 0.83$ & $19.17 \pm 0.51$ & $19.63 \pm 0.36$ & $19.22 \pm 0.80$ & $19.47 \pm 0.72$ & $19.15 \pm 0.19$ & $19.35 \pm 0.56$ \\
\hline $\mathrm{MCHC}\left(\mathrm{g} \mathrm{dL}^{-1}\right)$ & $33.83 \pm 0.98$ & $33.37 \pm 0.45$ & $33.85 \pm 1.14$ & $33.68 \pm 0.37$ & $33.68 \pm 0.29$ & $33.25 \pm 0.63$ & $33.57 \pm 0.69$ \\
\hline Thrombocytes $\left(\times 10^{3} \mu \mathrm{L}^{-1}\right)$ & $773 \pm 62.1 \mathrm{a}$ & $923 \pm 71.5 b$ & $838 \pm 54.5 \mathrm{ab}$ & $859 \pm 94.1 \mathrm{ab}$ & $876 \pm 64.4 \mathrm{ab}$ & $826 \pm 105.4 \mathrm{ab}$ & $799 \pm 98.0 \mathrm{ab}$ \\
\hline LYM (\%) & $93.88 \pm 1.02$ & $94.58 \pm 0.95$ & $89.35 \pm 8.28$ & $93.50 \pm 1.17$ & $94.73 \pm 1.14$ & $93.35 \pm 1.53$ & $93.50 \pm 1.37$ \\
\hline
\end{tabular}

Means ( $n=6 \pm$ standard deviation) followed by different lower-case letters within row are significantly different at $p<0.05$. BC — control bread; B1—bread enriched with milk and poppy; B2-bread enriched with carum, amaranth, and seeds; B3 - bread enriched with hazel nuts, seeds, and amaranth flour; B4-bread enriched with milk, amaranth flour, and seeds; B5-bread enriched with amaranth flour, seeds, yolk, and carum; B6 — bread enriched with milk, amaranth flour, seeds, and poppy; WBC—white blood cells; MCV—mean corpuscular volume; $\mathrm{MCH}-\mathrm{mean}$ corpuscular hemoglobin; MCHC-mean corpuscular hemoglobin concentration; LYM-lymphocytes.

The antioxidant status of rats fed with enriched breads was determined based on the reducing and antiradical abilities of serum, and changes in the activity of two enzymes involved in enzymatic antioxidant defense (Table 5). No statistically significant changes, affected by the studied diets, were observed in reducing and antiradical potential of rat serum. Serum superoxide dismutase activity was significantly reduced by all the studied diets (except B2 and B3). Serum catalase activity was significantly increased in rats fed with B3, B4, and B5 by about 90\%, 70\%, and 65\%, respectively, in comparison with BC. Contrary to these results, the B2 diet promoted a significant reduction in the catalase activity. The observed changes cannot be directly explained by a higher amount of phenolics introduced to diet by functional additives. It may be speculated that other factors, such as microbiota action (e.g., release of bound phenolics and restructuration of phenolics structure), interaction of phenolics with food components (protein- and starch-phenolics interactions), and release of bioactive peptides from proteins, play an important role in the creation of final effects.

Table 5. The antioxidant status of rats' serum after feeding with buckwheat breads.

\begin{tabular}{|c|c|c|c|c|}
\hline & $\begin{array}{l}\text { Catalase Activity } \\
\left(\mathrm{kU} \mathrm{dL} \mathrm{dL}^{-1}\right)\end{array}$ & $\begin{array}{l}\text { SOD Activity } \\
\left(\mathbf{k U ~ d L ^ { - 1 } )}\right.\end{array}$ & $\begin{array}{l}\text { Antiradical Activity } \\
\left(\text { mol TE } \mathrm{dL}^{-1}\right)\end{array}$ & $\begin{array}{l}\text { Reducing Potential } \\
\quad\left(\mathrm{molTE} \mathrm{dL}^{-1}\right)\end{array}$ \\
\hline $\mathrm{BC}$ & $67.67 \pm 20.9 b$ & $16.24 \pm 2.4 \mathrm{e}$ & $273.8 \pm 37.1 \mathrm{ab}$ & $36.1 \pm 0.83$ \\
\hline B1 & $61.03 \pm 7.7 b$ & $5.27 \pm 1.6 b c$ & $299.5 \pm 8.3 b$ & $36.3 \pm 4.49$ \\
\hline B2 & $25.92 \pm 4.6 \mathrm{a}$ & $16.11 \pm 0.7 \mathrm{e}$ & $298.1 \pm 15.6 \mathrm{ab}$ & $36.9 \pm 0.73$ \\
\hline B3 & $116.09 \pm 13.3 \mathrm{~cd}$ & $10.63 \pm 1.9 \mathrm{de}$ & $306.0 \pm 12.1 \mathrm{~b}$ & $35.8 \pm 3.29$ \\
\hline B4 & $111.49 \pm 17.2 \mathrm{~cd}$ & $5.44 \pm 0.9 \mathrm{bc}$ & $307.8 \pm 10.2 \mathrm{ab}$ & $37.6 \pm 3.70$ \\
\hline B5 & $128.16 \pm 20.1 \mathrm{~d}$ & $4.43 \pm 1.1 \mathrm{abc}$ & $298.4 \pm 19.2 \mathrm{ab}$ & $37.7 \pm 0.42$ \\
\hline B6 & $80.46 \pm 18.9 \mathrm{bc}$ & $4.71 \pm 1.2 \mathrm{abc}$ & $287.6 \pm 4.2 \mathrm{a}$ & $39.1 \pm 2.66$ \\
\hline
\end{tabular}

Means ( $n=6, \pm$ standard deviation) followed by different lower-case letters in columns are significantly different at $p<0.05$. BC — control bread; B1—bread enriched with milk and poppy; B2 — bread enriched with carum, amaranth and seeds; B3-bread enriched with hazel nuts, seeds, and amaranth flour; B4-bread enriched with milk, amaranth flour, and seeds; B5—-bread enriched with amaranth flour, seeds, yolk, and carum; B6 — bread enriched with milk, amaranth flour, seeds, and poppy; TE-Trolox equivalent. 
The beneficial effects observed after consumption of buckwheat or buckwheat-enriched food products is well documented in animal and human studies [20]. Stokić et al., [21] reported that buckwheat protein extract reduces hepatic triacylglycerols concentration, adipose tissue weight, and hepatic lipogenesis in rats. The diet containing buckwheat-enriched wheat bread (at the level of 50\%) was also tested in normal-weight patients on statin therapy over one-month dietetic intervention. In comparison with the wheat bread, the enriched breads were characterized by 2.22 times higher total dietary fiber and 4.29 times higher total phenolics content and significantly decreased total and LDL-cholesterol. According to the literature data, buckwheat can reduce the concentration of cholesterol in the serum by increasing the fecal excretion of steroids, which is induced by the binding of steroids to undigested proteins [1]. Additionally, Świeca [4] reported that a high amount of flavonoids in buckwheat flour significantly decreases the digestibility of starch and proteins by formation of undigested complexes with both digestive enzymes and buckwheat proteins. The presence of such interactions in the phenolics-rich food has already been reported [22]. On the other hand, lowering of cholesterol content by buckwheat-rich diet may be due to a high content of dietary fiber, which effectively binds bile acid (produced from cholesterol) [23]. In comparison with previous studies performed with gluten-free rice-based breads and using similar ingredients [16], the lipid profile was not significantly different, although significant differences were found in the activities of AST and ALT. It is known that a buckwheat-rich diet may promote an increase in the activity of these liver markers that is linked with intensification of cholesterol metabolism [24]; however, in this study, such effect was not observed (compared to wheat or other gluten-free bread) [16]. Most importantly, similarly to the previous studies by Lee et al. [7], in the rats fed with the enriched bread, a decrease of ALT activity was observed (statistically insignificant, but a tendency was clearly visible).

An increase of the antioxidant status of rats after consumption of standard diets including bread crust glycated compounds with a high antioxidant potential was also previously described by Pastoriza et al. [25]. A positive effect of a diet enriched with buckwheat was also confirmed by Zduńczyk et al. [26]. Compared with the diet containing naked oat, a higher antioxidant capacity in vivo of the diet with buckwheat waste increased numerically, but not statistically, the activity of glutathione peroxidase and the level of TBARS. A similar observation was also found during the study concerning cardioprotective effects of diet with different grains on lipid profiles and antioxidative potential in obesity-induced rats [27]. Compared to the other studied diets, the buckwheat-rich diet caused a significant reduction of plasma TBARS and low-density lipoprotein cholesterol (LDL-C) $(p<0.05)$ and increased high-density lipoprotein (HDL-C). In summary, the basic buckwheat bread (BC) and the studied supplemented bread were characterized by a significantly higher antioxidant potential [8].

\section{Conclusions}

The results in this short-term experiment confirmed the usefulness and safety of functional ingredients for the production of bakery goods based on buckwheat flour. Breads enriched with functional ingredients have a beneficial influence on triacylglycerols concentration in the serum of rats, although the physiological relevance of our observations should be further examined in long-term studies on experimental animals and/or humans.

Author Contributions: Conceptualization, M.Ś. and J.R.; data curation, M.Ś., J.R., and J.S.; formal analysis, M.Ś. and J.R.; investigation, M.Ś., J.R., and J.S.; supervision, J.R.; visualization, M.Ś., U.Z., U.G.-D., and I.M.P.L.V.O.F; writing—original draft, M.Ś. and J.R.; writing—review and editing, M.Ś., J.R., J.S., U.Z., U.G.-D., and I.M.P.L.V.O.F. All authors have read and agreed to the published version of the manuscript.

Funding: This research was funded by the National Science Centre (NCN), grant OPUS number 2011/01/B/NZ9/00130. The APC was funded by the internal sources (statutory funds) of the Poznan University of Life Sciences.

Conflicts of Interest: The authors declare that there is no conflict of interest regarding the publication of this paper. 


\section{References}

1. Giménez-Bastida, J.A.; Piskuła, M.; Zieliński, H. Recent advances in development of gluten-free buckwheat products. Trends Food Sci. Technol. 2015, 44, 58-65. [CrossRef]

2. Regula, J.; Smidowicz, A. Share of dietary supplements in nutrition of coeliac disease patients. Acta Sci. Pol. Technol. Aliment. 2014, 13, 301-307. [CrossRef] [PubMed]

3. Christa, K.; Soral-Śmietana, M. Buckwheat grains and buckwheat products - Nutritional and prophylactic value of their components-A review. Czech J. Food Sci. 2008, 26, 153-162. [CrossRef]

4. Swieca, M. Potentially bioaccessible phenolics, antioxidant activity and nutritional quality of young buckwheat sprouts affected by elicitation and elicitation supported by phenylpropanoid pathway precursor feeding. Food Chem. 2016, 192, 625-632. [CrossRef]

5. Regula, J.; Cerba, A.; Suliburska, J.; Tinkov, A.A. In vitro bioavailability of calcium, magnesium, iron, zinc, and copper from gluten-free breads supplemented with natural additives. Biol. Trace Elem. Res. 2018, 182, 140-146. [CrossRef]

6. Świeca, M. Elicitation and treatment with precursors of phenolics synthesis improve low-molecular antioxidants and antioxidant capacity of buckwheat sprouts. ACTA Sci. Pol. Technol. Aliment. 2016, 15, 17-28. [CrossRef]

7. Lee, C.-C.; Shen, S.-R.; Lai, Y.-J.; Wu, S.-C. Rutin and quercetin, bioactive compounds from tartary buckwheat, prevent liver inflammatory injury. Food Funct. 2013, 4, 794-802. [CrossRef]

8. Dziki, D.; Różyło, R.; Gawlik-Dziki, U.; Świeca, M. Current trends in the enhancement of antioxidant activity of wheat bread by the addition of plant materials rich in phenolic compounds. Trends Food Sci. Technol. 2014, 40, 48-61. [CrossRef]

9. Reeves, P.G. Components of the AIN-93 Diets as Improvements in the AIN-76A Diet. J. Nutr. 1997, 127, 838S-841S. [CrossRef]

10. Available online: https://ndb.nal.usda.gov/ (accessed on 17 October 2019).

11. Dembinska-Kiec, A.; Nastalski, J.W. Laboratory Diagnostics with the Elements of Clinical Biochemistry; Urban \& Partner: Wrocław, Poland, 2002.

12. Singleton, V.; Rossi, J. Colorimetry of total phenolics with phosphomolybdic-phosphotungstic acid reagents. Am. J. Enol. Vitic. 1965, 16, 144-158.

13. Re, R.; Pellegrini, N.; Proteggente, A.; Pannala, A.; Yang, M.; Rice-Evans, C. Antioxidant activity applying an improved ABTS radical cation decolorization assay. Free Radic. Biol. Med. 1999, 26, 1231-1237. [CrossRef]

14. Oyaizu, M. Studies on products of browning reaction-Antioxidative activities of products of browning reaction prepared from glucosamine. Jpn. J. Nutr. 1986, 44, 307-315. [CrossRef]

15. Claiborne, A. Catalase activity. In Handbook of Methods for Oxygen Radical Research; CRC Press: Boca Raton, FL, USA, 1985; pp. 283-284.

16. Swieca, M.; Reguła, J.; Suliburska, J.; Złotek, U.; Gawlik-Dziki, U. Effects of gluten-free breads, with varying functional supplements, on the biochemical parameters and antioxidant status of rat serum. Food Chem. 2015, 182, 268-274. [CrossRef] [PubMed]

17. Zhou, J.Y.; Prognon, P. Raw material enzymatic activity determination: A specific case for validation and comparison of analytical methods-the example of superoxide dismutase (SOD). J. Pharm. Biomed. Anal. 2006, 40, 1143-1148. [CrossRef] [PubMed]

18. Nishi, S.K.; Kendall, C.W.C.; Bazinet, R.P.; Bashyam, B.; Ireland, C.A.; Augustin, L.S.A.; Blanco Mejia, S.; Sievenpiper, J.L.; Jenkins, D.J.A. Nut consumption, serum fatty acid profile and estimated coronary heart disease risk in type 2 diabetes. Nutr. Metab. Cardiovasc. Dis. 2014, 24, 845-852. [CrossRef]

19. Sakač, M.; Torbica, A.; Sedej, I.; Hadnađev, M. Influence of breadmaking on antioxidant capacity of gluten free breads based on rice and buckwheat flours. Food Res. Int. 2011, 44, 2806-2813. [CrossRef]

20. Kayashita, J.; Shimaoka, I.; Nakajoh, M.; Kato, N. Feeding of buckwheat protein extract reduces hepatic triglyceride concentration, adipose tissue weight, and hepatic lipogenesis in rats. J. Nutr. Biochem. 1996, 7 , 555-559. [CrossRef]

21. Stokić, E.; Mandić, A.; Sakač, M.; Mišan, A.; Pestorić, M.; Šimurina, O.; Jambrec, D.; Jovanov, P.; Nedeljković, N.; Milovanović, I.; et al. Quality of buckwheat-enriched wheat bread and its antihyperlipidemic effect in statin treated patients. LWT Food Sci. Technol. 2015, 63, 556-561. [CrossRef] 
22. Swieca, M.; Gawlik-Dziki, U.; Dziki, D.; Baraniak, B.; Czyż, J. The influence of protein-flavonoid interactions on protein digestibility in vitro and the antioxidant quality of breads enriched with onion skin. Food Chem. 2013, 141, 451-458. [CrossRef]

23. Dziedzic, K.; Górecka, D.; Kucharska, M.; Przybylska, B. Influence of technological process during buckwheat groats production on dietary fibre content and sorption of bile acids. Food Res. Int. 2012, 47, 279-283. [CrossRef]

24. Tomotake, H.; Yamamoto, N.; Yanaka, N.; Ohinata, H.; Yamazaki, R.; Kayashita, J.; Kato, N. High protein buckwheat flour suppresses hypercholesterolemia in rats and gallstone formation in mice by hypercholesterolemic diet and body fat in rats because of its low protein digestibility. Nutrition 2006, 22, 166-173. [CrossRef] [PubMed]

25. Pastoriza, S.; Roncero-Ramos, I.; Rufián-Henares, J.Á.; Delgado-Andrade, C. Antioxidant balance after long-term consumption of standard diets including bread crust glycated compounds by adult rats. Food Res. Int. 2014, 64, 106-113. [CrossRef] [PubMed]

26. Zduńczyk, Z.; Flis, M.; Zieliński, H.; Wróblewska, M.; Antoszkiewicz, Z.; Juśkiewicz, J. In vitro antioxidant activities of barley, husked oat, naked oat, triticale, and buckwheat wastes and their influence on the growth and biomarkers of antioxidant status in rats. J. Agric. Food Chem. 2006, 54, 4168-4175. [CrossRef] [PubMed]

27. Kim, J.Y.; Shin, J.H.; Lee, S.S. Cardioprotective effects of diet with different grains on lipid profiles and antioxidative system in obesity-induced rats. Int. J. Vitam. Nutr. Res. 2012, 82, 85-93. [CrossRef]

(C) 2019 by the authors. Licensee MDPI, Basel, Switzerland. This article is an open access article distributed under the terms and conditions of the Creative Commons Attribution (CC BY) license (http://creativecommons.org/licenses/by/4.0/). 